\title{
RESEARCH ON LARGE-SCALE TURBINE DISK OF WROUGHT GH4738 SUPERALLOY USING MICROSTRUCTURE EVOLUTION PRECISION CONTROL MODELS COMBINED WITH INTEGRATED SIMULATION METHODS
}

\author{
Zhihao YAO, Linhan Li, Maicang Zhang, Jianxin DONG Xishan Xie \\ High Temperature Materials Research and Application Laboratory, \\ University of Science and Technology Beijing, Beijing, 100083, China.
}

Keywords GH4738, superalloy, deformation, microstructure, simulation, forging, hydraulic press.

\begin{abstract}
The large-scale flue gas turbine disk $\Phi 1450 \mathrm{~mm}$ of GH4738 (Waspaloy) nickel based superalloy has been successfully forged by hot deformation using $800 \mathrm{MN}$ die forging hydraulic press, which contributed to microstructure evolution precision control models combined with integrated simulation method at different deformation conditions. Constitutive equations and grain structure evolution models of GH4738 alloy were constructed and used in Deform3D for achieving integrated simulation of the complete forging process for the turbine disk (from preheating billet for free forging to die forging).

The integrated numerical simulation was used for an experimental disk with the diameter of $\Phi 300 \mathrm{~mm}$ before forging the large-scale disk. Comparison between integrated simulations and actual forging results show that the simulated microstructure are in accordance with the actual results and the integrated simulation method excelled traditional simple single stage simulation. Finally, the integrated numerical simulation of the $\Phi 1450 \mathrm{~mm}$ turbine disk die forging was also carried out through orthogonal experiment methods according to initial average grain size, temperatures, strain and strain rate and so on, and the optimal deformation parameters were chosen for forging using a $800 \mathrm{MN}$ hydraulic press. The results indicate that this method has shown a high correlation with actual microstructure distribution of GH4738 superalloy disk. Besides, the mechanical properties, grain sizes and microstructural homogeneity of the large-scale flue gas turbine disk have reached up to the specification level of HG/T3650-2012 (equivalent to AMS 5704G). In conclusion, the microstructure evolution models and integrated simulation methods of GH4738 alloy have provided a new method for making large-scale disk forgings.
\end{abstract}

\section{Introduction}

The ability to predict and control the microstructure of superalloys during thermomechanical processing is critical to the development of enhanced service properties. For example, prior work on wrought GH4738 has sought to quantify recrystallization and grain growth behavior, including the effects of multi-step deformation and final annealing on microstructure evolution [1]. However, single deformation simulation often cannot represent the whole deformation process and lead to inaccuracies with the potential of the forged work piece not meeting specification. Recent efforts on integrated simulation of the deformation process have been developed [2-4]. GH4738 alloy is an age-hardenable nickel based superalloy with excellent strength properties, good corrosion and oxidation resistance at temperatures up to 
$760-870^{\circ} \mathrm{C}$. So it is often applied in extreme environments and used for gas turbine blades, seals, rings, shafts and turbine disks [5-7]. In actual production, in order to obtain higher tensile strength and low cycle fatigue properties, turbine disk should have a homogeneous fine grain structure. So, microstructure control is an important factor for properties during turbine forging especially for grain size requirements. Much work has been published on microstructural control [1-15, 20-22].

With the development of simulation techniques and its application in metal forming processes, changes have occurred in design methodologies. The simulation research for metal forming processes can be divided into three levels [4]. Global modelling (prediction of deformation load or work using the slab method and upper bound technique), local modelling (calculation of thermomechanical variables using Finite Element Method (FEM)) and microstructure modelling (evaluation of the metallurgical and mechanical properties including microstructure, texture and anisotropy). Till now, a lot of work has been done on the second level (local modelling) to simulate 2D or 3D forming processes and considerable achievements have been made.

However, during the forming process, the material undergoes a series of microstructural changes, such as dynamic/static recovery, recrystallization and grain growth. All these influence the forming process (such as forming force, distribution of temperature, strain and stain rate) and the properties of the final products (including the strength, ductility and toughness). Therefore, microstructural modelling forms a vital part of simulating the overall thermo-mechanical process. It is very important to combine microstructural evolution and FEM simulation to develop a general model for the complete process. Today research on the third level (mechanical and metallurgical properties) is receiving increased attention. Work in simulating the microstructure and thermomechanics have been studied extensively for a wide range of metals and alloys. Sellars et al. [16] presented microstructure simulation in the hot rolling of steel strip and plate. Semi-empirical mathematical models of microstructural evolution using the thermomechanical parameters have been established for C-Mn steel. Yada [17] has found the critical strain to be independent of both the initial grain size and strain rate. Devadas [18] made a summary of the earlier work, to predict the grain size and the recrystallization kinetics during the hot rolling of C-Mn steel. Karhausen and Kopp [4] first introduced the micro-simulating technique into the FEM modelling of the forging processes. $\mathrm{Xu}$ [19] first produced a model simulating microstructural evolution in ring rolling of steel. Shen [1] modelled microstructural development during forging of Waspaloy. All these works focused on microstructure prediction without considering optimal design and integrated simulation. Yao $[2,3]$ constructed precise grain evolution model that has been applied to the forging of a super large-scale disk of GH4738 in China.

Although there are some publications on microstructure prediction and optimum design in metal forming processing, there are several issues that have not yet been studied. For example, forging of large-scale turbine disk and based on an integrated simulation with microstructure model have not been reported for GH4738. This paper will propose a new approach based on evolution of microstructure in a combined integrated simulation $[2,3]$ applied to a gas turbine disk of GH4738 superalloy of over $1000 \mathrm{~mm}$ diameter. The model shall incorporate billet heating with die forging. The model shall not only address the recrystallized grain size and extent, unrecrystallized regions are also considered based on prior researchers' experience 
[20-23]. Different kinds of design variables are applied, including state parameters for initial grain size of billet and process variables. The flowchart of microstructure control for large disks based on integrated simulation design and processes variables in Deform 3D simulation is described. The optimization scheme is demonstrated with the microstructure integrated simulation of a turbine disk forging made of GH4738 in the non-isothermal forging process.

\section{Constructing of Microstructural Evolution Models.}

The experimental GH4738 alloy was used to build microstructure evolution models. The Gleeble thermal physical simulation specimen size is $8 \mathrm{~mm}$ diameter and $12 \mathrm{~mm}$ tall. Constitutive equations and microstructure evolution precision control models of GH4738 superalloy have been systematically constructed by the processes outlined by [2]. The deformation processing of GH4738 for constructing models is shown in Figure 1.
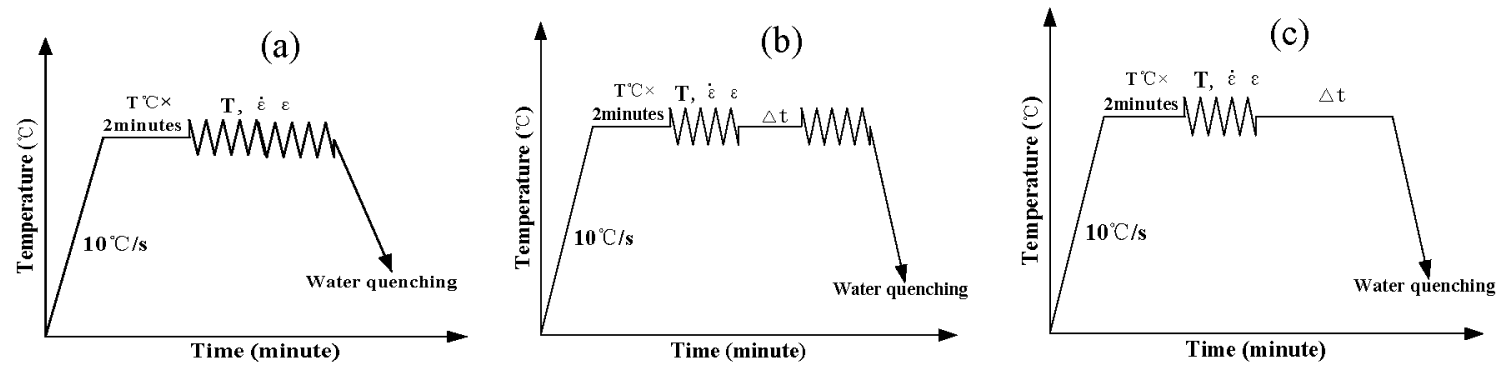

Figure 1. Deformation processing of GH4738 alloy; (a) dynamic recrystallization-DRX; (b) metadynamic recrystallizaiton and static recrystallization MDRX/SRX by single/double hit hot compression tests; (c) deformation and heat treatment for grain growth.

The hot deformation behavior of different initial grain sizes has been studied using hot compression tests via the Gleeble-1500. Correlation between flow stress and process parameters and microstructure evolution was characterized in the temperature range $1000-1160{ }^{\circ} \mathrm{C}$, strain rate range $0.01-10 \mathrm{~s}^{-1}$ and engineering strain range $15-70 \%$. Meta-dynamic recrystallization and static recrystallization was studied in the temperature range $1040-1120{ }^{\circ} \mathrm{C}$, strain rate range $0.1-10 \mathrm{~s}^{-1}$ and engineering strain range $15-50 \%$ with holding times of $0-45 \mathrm{~s}$. Grain growth (GG) behavior was determined in the temperature range $980-1140^{\circ} \mathrm{C}$ with holding times $0-4 \mathrm{~h}$. The results show that recrystallization behavior of GH4738 alloy is significantly affected by initial grain size, deformation temperature, strain and strain rate. Constitutive equations and microstructural evolution models are shown in Table 1.

Table 1. Constitutive Equations and Grain Structure Evolution Models for GH4738 Alloy ${ }^{[2,3]}$

Flow stress model during hot deformation

$$
\begin{aligned}
& \dot{\varepsilon}=2.49 \times 10^{18}[\sinh (0.00345 \sigma)]^{4.02} \exp (-499000 / R T) \\
& Z=\dot{\varepsilon} \exp (499000 / R T) \\
& \bar{\sigma}_{p}=0.364 D_{0}^{-0.097} Z^{0161}
\end{aligned}
$$




$$
\begin{array}{ll}
\bar{\sigma}_{p}=0.1613 D_{0}^{-0.052} Z^{0.174} & 1040^{\circ} \mathrm{C} \\
\bar{\sigma}_{p}=0.0829 D_{0}^{-0.038} Z^{0.187} & \left(1040<T \leq 1160^{\circ} \mathrm{C}\right) \\
\bar{\varepsilon}_{p}=1.591 \times 10^{-6} D_{0}^{0.301} Z^{0.222} & \left(1000 \leq T<1040^{\circ} \mathrm{C}\right) \\
\bar{\varepsilon}_{p}=2.803 \times 10^{-6} D_{0}^{0.290} Z^{0.211} & 1040^{\circ} \mathrm{C} \\
\bar{\varepsilon}_{p}=1.436 \times 10^{-6} D_{0}^{0.326} Z^{0.224} & \left(1040<T \leq 1160^{\circ} \mathrm{C}\right) \\
\varepsilon_{\mathrm{c}}=0.851 \varepsilon_{p} & \\
\left(\dot{\varepsilon}-\text { strain rate, } \mathrm{s}^{-1} ; \mathrm{R}-\mathrm{gas} \quad \text { constant equal to } 8.314 ; \mathrm{T}-\mathrm{absolutely} \text { temperature, } \mathrm{K} ;\right. \\
Z-Z \text {-Zener-Hollomon parameter; } \bar{\sigma}_{p}-\text { equivalent peak stress, MPa; } \bar{\varepsilon}_{p}-\text { equivalent peak } \\
\text { strain; } \left.\varepsilon_{\mathrm{c}} \text {-critical strain, } \varepsilon_{p}-\text { peak strain; } D_{0}-\text { initial average grain size, } \mu \mathrm{m}\right)
\end{array}
$$

Dynamic recrystallization model (DRX model)

$$
\begin{array}{ll}
\mathrm{X}_{\mathrm{dyn}}=1-\exp \left\{-\ln 2\left[\varepsilon / \varepsilon_{0.5}\right]^{2.09}\right\} & \left(1000 \leq T<1040^{\circ} \mathrm{C}\right) \\
\mathrm{X}_{\mathrm{dyn}}=1-\exp \left\{-\ln 2\left[\varepsilon / \varepsilon_{0.5}\right]^{2.57}\right\} & 1040^{\circ} \mathrm{C} \\
\mathrm{X}_{\mathrm{dyn}}=1-\exp \left\{-\ln 2\left[\varepsilon / \varepsilon_{0.5}\right]^{2.13}\right\} & \left(1040<T \leq 1160^{\circ} \mathrm{C}\right) \\
\left(\mathrm{X}_{\text {Drx }}\right. \text {-fraction of DRX) } & \left(1000 \leq T<1040^{\circ} \mathrm{C}\right) \\
\bar{\varepsilon}_{0.5}=0.0238 D_{0}^{0.007} Z^{0.0849} \mathrm{n}=2.09 & 1040^{\circ} \mathrm{C} \\
\bar{\varepsilon}_{0.5}=0.056 D_{0}^{0.0952} Z^{0.0527} \mathrm{n}=2.57 & \left(1040<T \leq 1160^{\circ} \mathrm{C}\right) \\
\bar{\varepsilon}_{0.5}=0.0016 D_{0}^{0.2709} Z^{0.1147} \mathrm{n}=2.13 & \left(1000 \leq T<1040^{\circ} \mathrm{C}\right) \\
\mathrm{d}_{\text {Drx }}=1.13 \times 10^{5} Z^{-0.206} & 1040^{\circ} \mathrm{C} \\
\mathrm{d}_{\text {Drx }}=55.65 Z^{-0.0372} & \left(1040<T \leq 1160^{\circ} \mathrm{C}\right) \\
\mathrm{d}_{\text {Drx }}=3.66 \times 10^{5} Z^{-0.2218} & \\
\left(\bar{\varepsilon}_{0.5}-\text { strain of } 50 \% \text { DRX; } \mathrm{d}_{\text {Drx }}-\text { grain size of DRX, } \mu \mathrm{m}\right)
\end{array}
$$

Meta-dynamic recrystallization/Static recrystallization model (MDRX and SRX model)

$$
\begin{aligned}
& t_{0.5 M d r x / S r x}=6.68 \times 10^{-4} D_{0}^{-0.113} \dot{\varepsilon}^{0.183} \varepsilon^{-1.69} \exp \left(\frac{48743}{R T}\right) \\
& X_{M d x x / S r x}=1-\exp \left[-\ln 2\left(\frac{t}{t_{0.5}}\right)^{0.4}\right] \\
& d_{M d r x / S r x}=4.6 \times 10^{5} D_{0}^{0.078} \dot{\varepsilon}^{-0.042} \varepsilon^{-0.35} \exp (121363 / R T)
\end{aligned}
$$


$\left(t_{0.5 \mathrm{Mdr} / \mathrm{Srx}}-\right.$ time of $50 \%$ MDRX and SRX, s; $\mathrm{X}_{\mathrm{Mdrx} / \mathrm{Srx}}-$ fraction of MDRX and SRX;

$d_{\mathrm{mdrx} / \mathrm{Srx}}-$ grain size of MDRX and SRX, $\mu \mathrm{m}$ )

Grain growth model

$$
\begin{aligned}
& d^{3.67}=d_{0}^{3.67}+3.984 \times 10^{20} \cdot t^{2.29} \cdot \exp (-490321 / R T) \quad t<10 \mathrm{~min} \\
& d=2.18 \times 10^{-32} \cdot T^{10.84} \quad\left(1040<T \leq 1160^{\circ} \mathrm{C}\right) \quad t \geq 10 \mathrm{~min}
\end{aligned}
$$

$\left(d-\right.$ grain size, $\mu \mathrm{m} ; d_{0}-$ initial grain size, $\left.\mu \mathrm{m}\right)$

The microstructure models are achieved based on Gleeble-1500 thermal physics simulation experimental data, including single and double pass compression of different deformation parameters. During simulation, multi-factors are considered including temperature, stress, strain, strain rate, grain sizes and time to describe comprehensive and quantitative microstructure evolution during hot deformation for GH4738 alloy. The physical properties of GH4738 alloy required for simulation such as density, Poisson's ratio, thermal conductivity, thermal expansion coefficient and other data are obtained from literature [2, 3, 23]. The simulation describe microstructure evolution during the hot deformation process, and also to predict the effect on forgings from processes such as billet heating, transfer, dwelling time and cooling. In order to predict temperature, the appropriate heat transfer coefficients between forging, dies and air environment were determined by previous experiments and studies. Through the effect of lubricant on the friction coefficient is also considered and set to 0.2 during deformation.

Simulation using Deform3D software, applied the secondary development MSC.SUPERFORM algorithm [3], the use of FORTRAN statements from the flowchart shown on Figure 2, and applying the algorithms described Table 1. In order to achieve the multi-stage continuous process simulation, the computed results for each operation is set as the initial value for the next stage in the simulation processes.

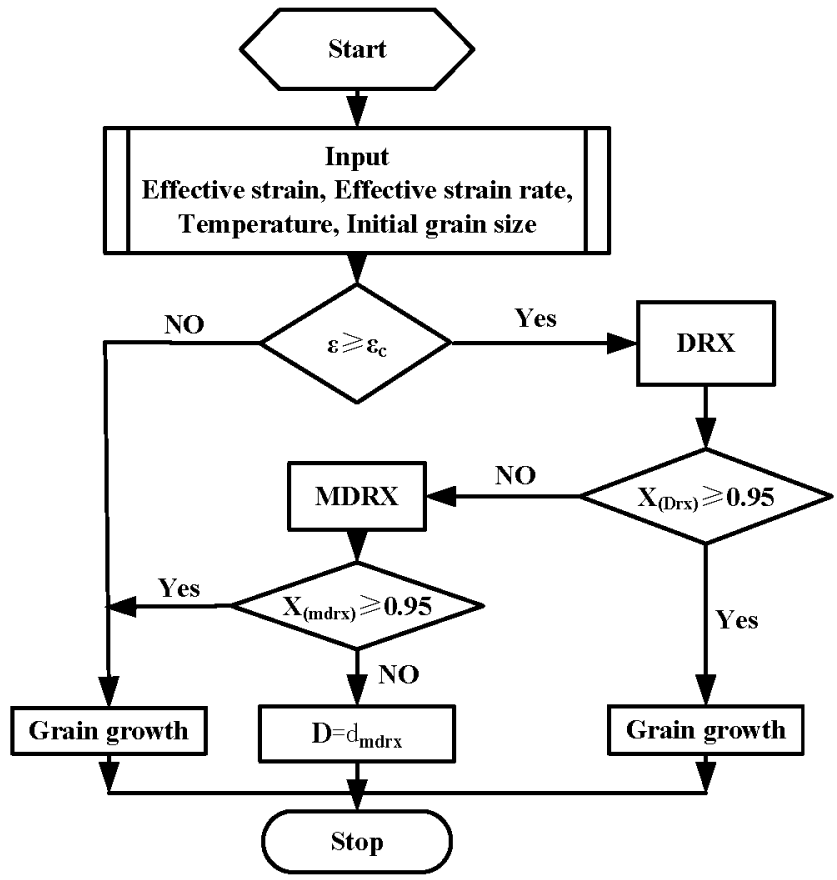


Figure 2. Flow chart of finite element module for computing alloy microstructure evolution.

\section{The Integrated Numerical Simulation}

An integrated numerical simulation method from heating billet for free forging to die forging and air cooling has been applied to the forging process simulation for GH4738 alloy. A complete model has been built, incorporating microstructure evolution models [2], into finite element software Deform $3 \mathrm{D}^{\mathrm{TM}}$ by means of the user subroutines to predict microstructure evolution during hot forging. A series of constitutive equations and grain structure evolution models of GH4738 alloy should be used for the effects of processing parameters such as stress, temperature, strain rate and grain size and so on. The dynamic recrystallization models were adopted in single deformation simulation previously. Microstructural changes may occur during billet heating, transfer, dwell and air cooling in the simulated these operations. The models shall incorporate microstructure evolution by dynamic recrystallization, metadynamic recrystallization, static recrystallization and grain growth.

Figure 3 outlines the production route for the GH4738 forging. A large number of papers have published dealing with simulation of turbine disk forging, single deformation simulations have been focused on stage 3 and 7 (Figure 3), while continuous and complete turbine disk deformation have not been extensively covered.

In practice, final properties and microstructure are influenced by whole forging process not only a single deformation, the history of deformation must be considered. Single simulation may cause two issues, one is the effect of billet heating, forging transportation and air cooling influence after deformation are ignored or unconsidered. The second problem is regional and sectional models cannot represent the overall processes. Continuity and hereditary of microstructure must be fully considered. Based on above analysis, the overall processes should be considered and the influence of each stage on forging microstructure should be precisely controlled. From first operation (Heating Billet) to eighth stage (Air cooling) described in Figure 3 should be designed to control the independent variable at each stage. Finally, the integrated simulation method can provide a theoretical guide for successful disk production route.

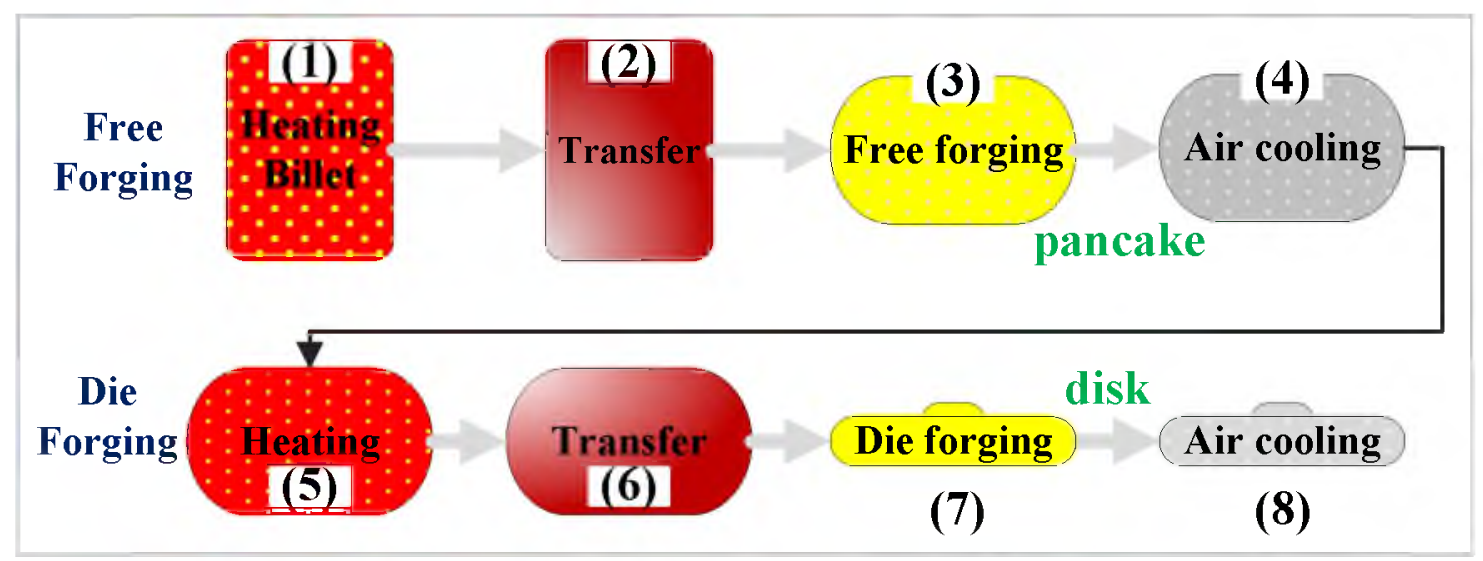

Figure 3. Forging process of GH4738 alloy turbine disk.

In this paper, the integrated simulation for turbine disk manufacture is adopted from heating billet to air cooling to achieve microstructure evolution through precise simulation prediction 
for GH4738 alloy.

\section{Simulation and Verification for Diameter of $\Phi 300 \mathrm{~mm}$ Turbine Disk}

An integrated numerical simulation was initially used for the production of a $\Phi 300 \mathrm{~mm}$ diameter of disks. The simulation results showed that the hot working window should be in the temperature range $1000-1140^{\circ} \mathrm{C}$, the deformation rate range $10-25 \mathrm{~mm} / \mathrm{s}$. A $\Phi 300 \mathrm{~mm}$ turbine disk was forged by hydraulic press using the simulation deformation parameters. Results from the disk produced were in good agreement with integrated simulated microstructural predictions. The integrated simulation method improved upon traditional single stage simulation. The simulation predictions are given in Figure 4. Therefore, it has been verified that the construction of microstructure evolution models of GH4738 alloy is reliable and the feasibility of the integrated simulation method is of great significance for accuracy control and prediction of turbine disk microstructure.
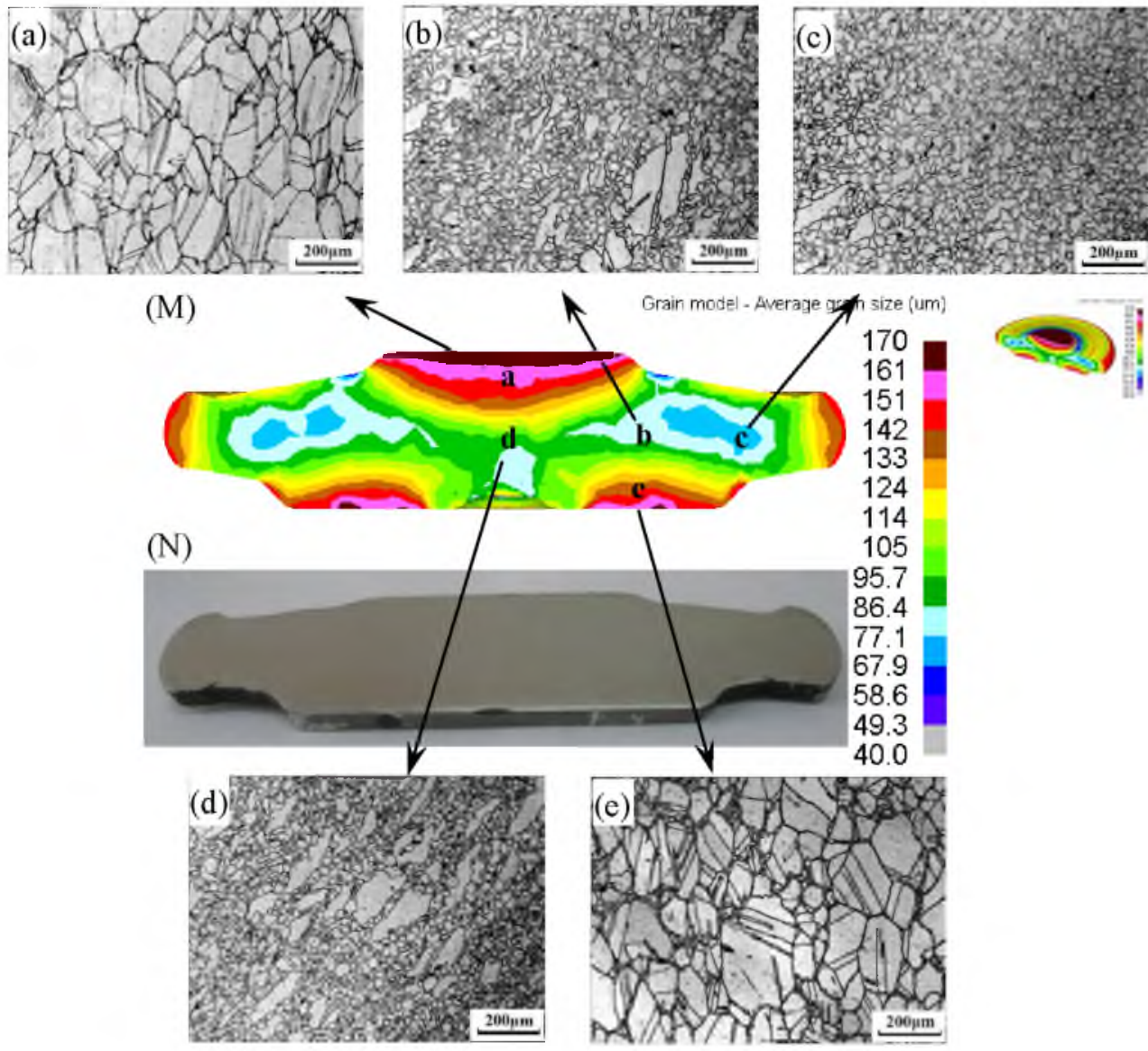

Figure 4. Comparison between simulated results and real distribution of average grain size in the vertical section along the axis of the $\$ 300 \mathrm{~mm}$ final work piece (M) final result of integrated simulation, (N)the vertical section along the axis of the real final workpiece, (a) (e)observed grain microstructure in location a e.

After forging the $\Phi 300 \mathrm{~mm}$ disk, it was heated treatment using the following thermal cycles by $1020^{\circ} \mathrm{C} / 4 \mathrm{~h} / \mathrm{OC}+845^{\circ} \mathrm{C} / 4 \mathrm{~h} / \mathrm{AC}+760^{\circ} \mathrm{C} / 16 \mathrm{~h} / \mathrm{AC}$. Mechanical test specimens were excised from the $\mathrm{R} / 2$ disk and room temperature tensile, elevated temperature $\left(540^{\circ} \mathrm{C}\right)$ tensile and $732^{\circ} \mathrm{C} / 550 \mathrm{MPa}$ stress rupture tests performed. The results are given in Tables 2 and 3 . Test 
results meet the gas expander specification value (HG/T 3650-2012) and with a margin for GH4738 alloy.

The results from the $\$ 300 \mathrm{~mm}$ turbine disk forging have validated integrated finite element simulation and demonstrate the potential to apply to more complex processing routes.

Table 2. Tensile Properties at Room and $540^{\circ} \mathrm{C}$ Temperature.

\begin{tabular}{ccccccc}
\hline No & $\begin{array}{c}\text { Test } \\
\text { temperature, } \\
\mathrm{T} /{ }^{\circ} \mathrm{C}\end{array}$ & Hardness & $\begin{array}{c}\text { Ultimate } \\
\text { strength, } \\
\mathrm{Rm} / \mathrm{MPa}\end{array}$ & $\begin{array}{c}\text { Yield } \\
\text { Strength, } \\
\mathrm{R}_{0.2} / \mathrm{MPa}\end{array}$ & $\begin{array}{c}\text { Elongation, } \\
\mathrm{A} / \%\end{array}$ & $\begin{array}{c}\text { Reduction of } \\
\text { area, Z/\% }\end{array}$ \\
\hline $\mathrm{R}-1$ & 23 & 361 & 1435 & 1070 & 20.0 & 28.0 \\
$\mathrm{R}-2$ & 23 & 358 & 1370 & 960 & 22.0 & 35.0 \\
$\mathrm{R}-3$ & 23 & 361 & 1385 & 955 & 21.0 & 32.0 \\
$\mathrm{R}-4$ & 23 & 360 & 1420 & 1115 & 20.0 & 29.0 \\
$\mathrm{H}-1$ & 540 & - & 1310 & 952 & 18.0 & 23.5 \\
$\mathrm{H}-2$ & 540 & - & 1275 & 908 & 18.0 & 23.0 \\
$\mathrm{H}-3$ & 540 & - & 1275 & 870 & 18.5 & 20.0 \\
$\mathrm{H}-4$ & 540 & - & 1300 & 1015 & 17.0 & 30.0 \\
\hline
\end{tabular}

Table 3. Combination Stress Rupture Properties at $732^{\circ} \mathrm{C} / 550 \mathrm{MPa}$.

\begin{tabular}{cccccc}
\hline No & Test temperature $\mathrm{T} /{ }^{\circ} \mathrm{C}$ & Stress $/ \mathrm{MPa}$ & Life $/ \mathrm{h}$ & $\delta / \%$ & $\Psi / \%$ \\
\hline S-1 & 732 & 550 & 45.0 & 42 & 62 \\
S-2 & 732 & 550 & 56.0 & 48 & 59 \\
S-3 & 732 & 550 & 61.0 & 34 & 60 \\
S-4 & 732 & 550 & 50.5 & 42 & 43 \\
\hline
\end{tabular}

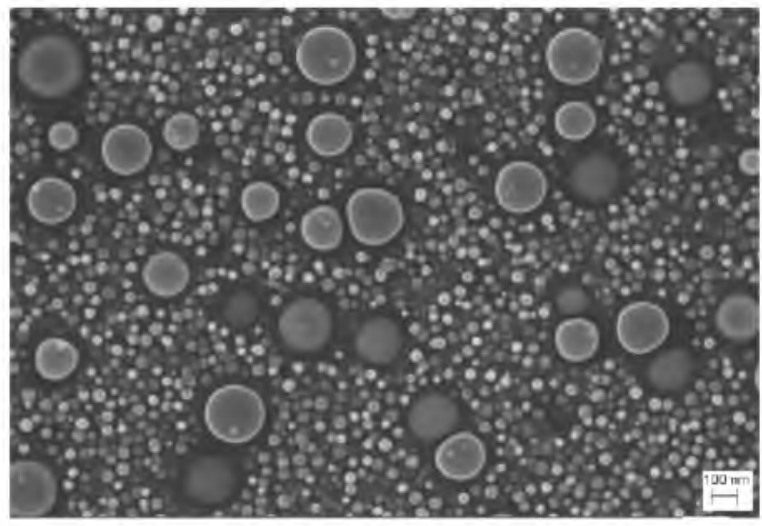

Figure 5. Typical distribution of gamma prime from $\Phi 300 \mathrm{~mm}$ work piece of GH4738 alloy.

\section{Ф1450mm Turbine Disk Orthogonal Experiment Simulation Methods}

The advantage of integrated simulation is that the whole process is considered with each operation influencing the final results. All eight processes can optimize deformation, so based on above integrated simulation methods, an orthogonal experiment $\mathrm{L}_{25}\left(4^{6}\right)$ was designed to optimize deformation process of a $\Phi 1450 \mathrm{~mm}$ turbine disk. Table 4 gives the parameters to be evaluated. 
The simulation parameter included initial grain size, free forging temperature $T_{1}$, transfer time $t_{1}$ for free forging operation, die temperature $T_{2}$ during free forging, initial work piece temperature $T_{3}$ for die forging, transfer time $t_{2}$ for die forging, die temperature $T_{4}$ and cooling conditions. Because initial grain size of work piece has been known in advance, six factors of $\mathrm{T} 1, \mathrm{t} 1, \mathrm{~T} 2, \mathrm{~T} 3, \mathrm{t} 2, \mathrm{~T} 4$ are only considered by an orthogonal test with four levels adopted in six factors.

A series of regression analysis on the simulation predictions was made evaluating the averaged grain sizes, extent of recrystallization, temperature, force of press and work piece cracking.

A typical integrated simulation example is shown in Figure 6 and 7. In Figure 6, the distribution of average predicted grain size for (a) initial billet; (b) after heating billet; (c) after free forging; (d) after air cooling for free forged disk; (e) after heating free forged disk for die forging; (f) after die forging; (g) after air cooling for die forged disk are shown. Microstructure evolution of GH4738 alloy after over 30h heating time grain size was in the range 178-186 $\mu \mathrm{m}$ (about ASTM No. 2). After free forging of billet, dynamic recrystallization

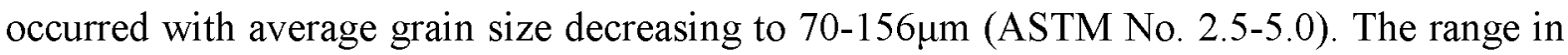
grain size results from the strain, temperature and strain rate distribution within the forging. Figure $6(d)$ indicates the minimum grain size is located at the work piece center and maximum grain size is around the work piece rim. After air cooling the grain size is further decreased due to Meta-dynamic recrystallization/Static recrystallization on alloy, as seen in Figure 6(d).

Table 4. Orthogonal Experiment Simulation Parameters.

\begin{tabular}{|c|c|c|c|c|c|}
\hline $\begin{array}{c}\text { Initial } \\
\text { temperature } \\
\text { of free } \\
\text { forging, } \\
\mathrm{T}_{1} /{ }^{\circ} \mathrm{C}\end{array}$ & $\begin{array}{c}\text { Transfer time } \\
\text { of free forging, } \\
\mathbf{t}_{1} / \mathrm{s}\end{array}$ & $\begin{array}{c}\text { Temperature of } \\
\text { die in Free } \\
\text { forging, } \\
\mathrm{T}_{2} /{ }^{\circ} \mathrm{C}\end{array}$ & $\begin{array}{c}\text { Initial } \\
\text { temperature of } \\
\text { die forging, } \\
\mathrm{T}_{3} /{ }^{\circ} \mathrm{C}\end{array}$ & $\begin{array}{l}\text { Transfer time } \\
\text { of forged disks } \\
\text { before die } \\
\text { forging, } \mathrm{t}_{2} / \mathrm{s}\end{array}$ & $\begin{array}{c}\text { Temperature of } \\
\text { die, } \mathrm{T}_{4} /{ }^{\circ} \mathrm{C}\end{array}$ \\
\hline $\begin{array}{c}1040 \\
1080,1120,114 \\
0\end{array}$ & $50,80,110,140$ & $\begin{array}{c}300,350,400,4 \\
50\end{array}$ & $\begin{array}{c}1040,1080, \\
1120,1140\end{array}$ & $50,80,110,140$ & $\begin{array}{c}300,350,400,4 \\
50\end{array}$ \\
\hline
\end{tabular}

After the forging work piece was heated again for die forging. Average grain size would increase significantly in the work piece as shown in Figure 6(e). The key deformation process for the large scale disk is die forging, and its mechanical properties are largely determined in this process. The average grain size of the die forged disk is shown as Figure 6(f). From the recrystallization occurring in the die forged disk indicating that recrystallization does not take place in the region of the disk surface. In other locations recrystallization occurs achieving a minimum grain size of less than $50 \mu \mathrm{m}$ (ASTM No. 5.5-6) in $\mathrm{R} / 2$ of disk. 


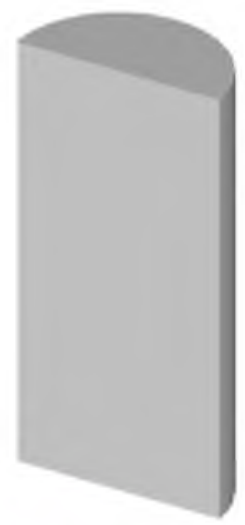

Grain model - Intal grain size (um)

(a)
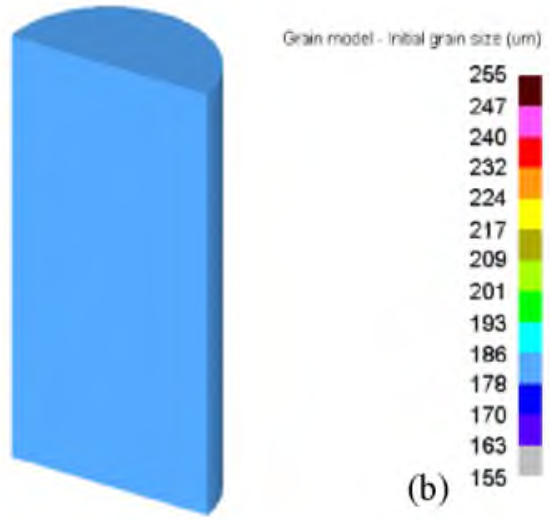

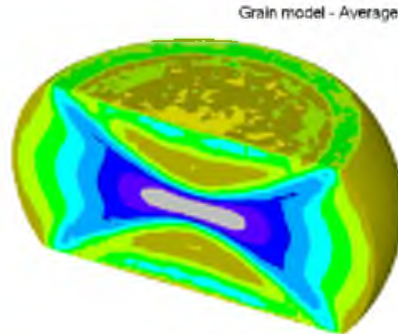

(c)

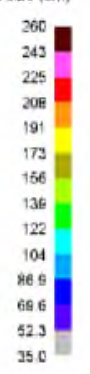

Grain model - Average grain size (um)

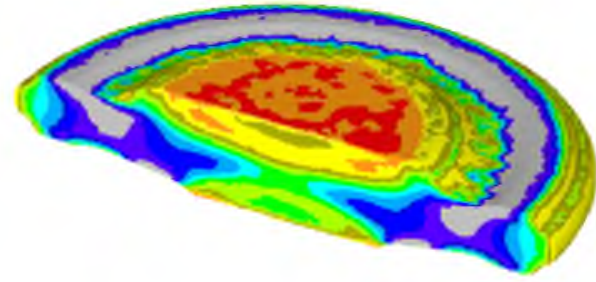

(f)

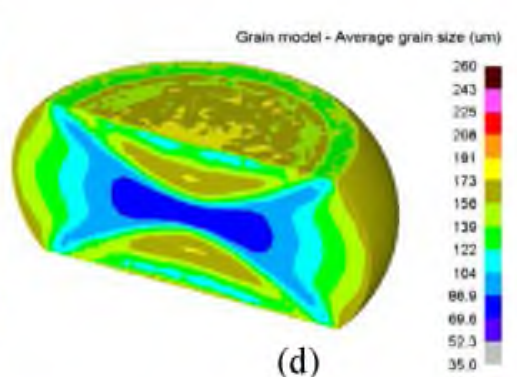

(d)

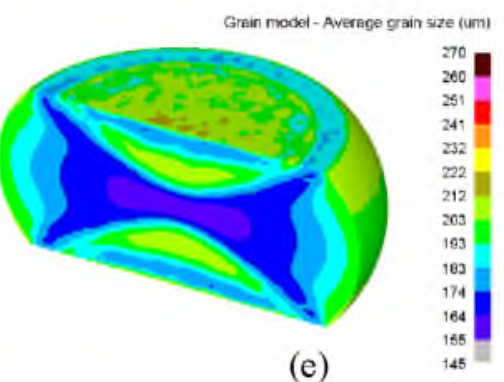

Grain model - Average grain size (um)

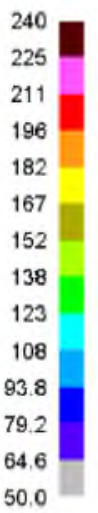

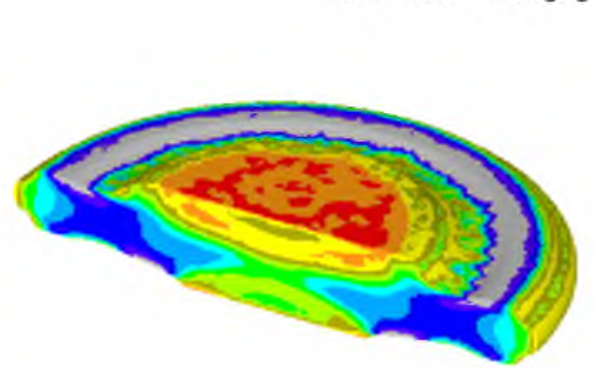

(g)
240
225
211
196
182
167
152
138
123
108
93.8
79.2
64.6
50.0

Figure 6. Distribution of average grain size of billet by integrated simulation for (a) initial billet; (b) after heating billet; (c) after free forging; (d) after air cooling for pancake; (e) after heating pancake and before die forging; ( $\mathrm{f}$ ) after die forging; (g) after air cooling for die forged disk.

During the complete forging press temperature change is important for microstructure evolution is shown in Figure 7. At the beginning of billet heating, it is assumed that the temperature is equal all over the billet. Billet temperature decreases during transfer to the forging press as shown in Figure 7(a). An insulating coating does reduce heat loss. Strain is critical, in the forging process and is dependent in die design but strain does influence the temperature distribution due to generating heat during deformation in the body of the work piece with temperature loss from the surface. The temperature distribution from the forging operations can be seen in Figure 7(b) and 7(d) for the pancake and die forging respectively. 

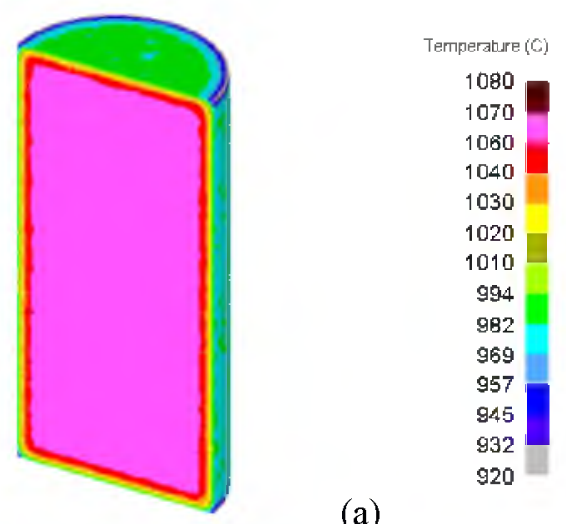

(a)
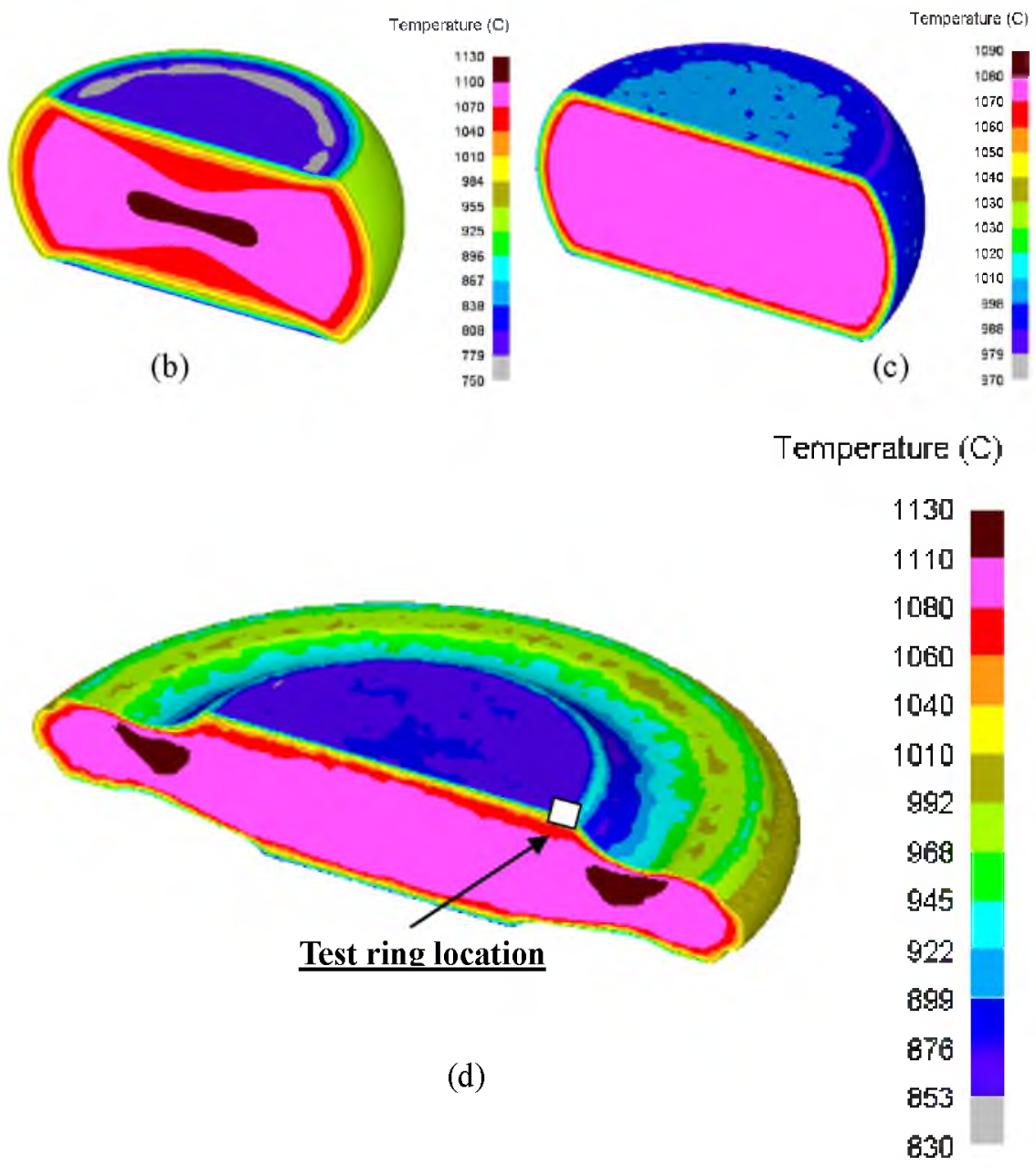

Figure 7. Temperature distribution of billet by integrated simulation for (a) after transfer heated billet; (b) after free forging; (c) after transfer heated pancake; (d) after die forging.

Finally, applying the orthogonal simulation combined with the experimental validation of the $\Phi 300 \mathrm{~mm}$ disk, the optimal deformation process is design for large scale turbine disk.

\section{Large-scale $\Phi 1450 \mathrm{~mm}$ Turbine Disk Forging and Mechanical Properties}

After analysis of the integrated simulation, the optimum deformation processes is chosen to forge the large turbine disk. In order to make produce the material for the large turbine disk a 
GH4738 alloy ingot was produced by the triple melting route. $\Phi 520 \mathrm{~mm}$ electrode was cast by VIM, ESR remelted to $\Phi 560 \mathrm{~mm}$ and VAR remelted to $\Phi 620 \mathrm{~mm}$ ingot. Final, the ingot was homogenized and cogged to a final size of $\Phi 620 \mathrm{~mm} \times 1250 \mathrm{~mm}$ long. The initial grain size was smaller $160 \mu \mathrm{m}$ (ASTM No. 2.5) after homogenization and cogging. Chemical composition of this GH4738 alloy is $\mathrm{C} 0.02$, Cr 18.74, Mo 4.44, Co 13.35, Ti 3.16, Al 1.53, S 0.0008 (8ppm), Ni balance.

Using the optimum deformation processes developed through the integrated simulation, the large scale billet was deformed by $800 \mathrm{MN}$ Die Forging Hydraulic Press, shown in Figure 8(a). The gas turbine disk of $\Phi 1450 \mathrm{~mm}$ was successful forge and is shown in Figure 8(b).

(a)

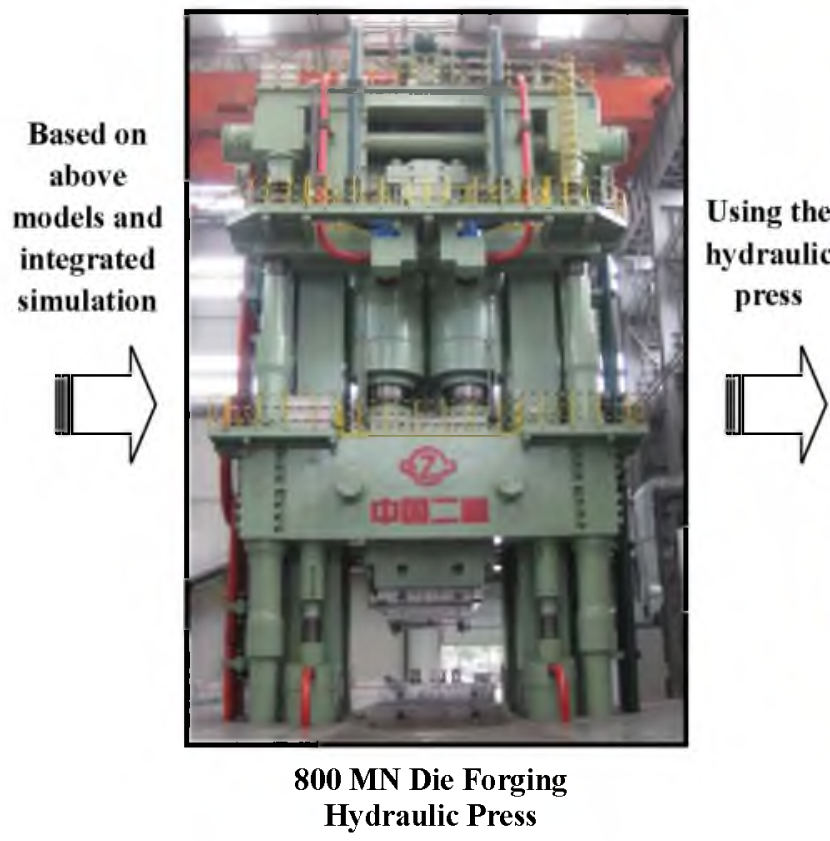

(b)

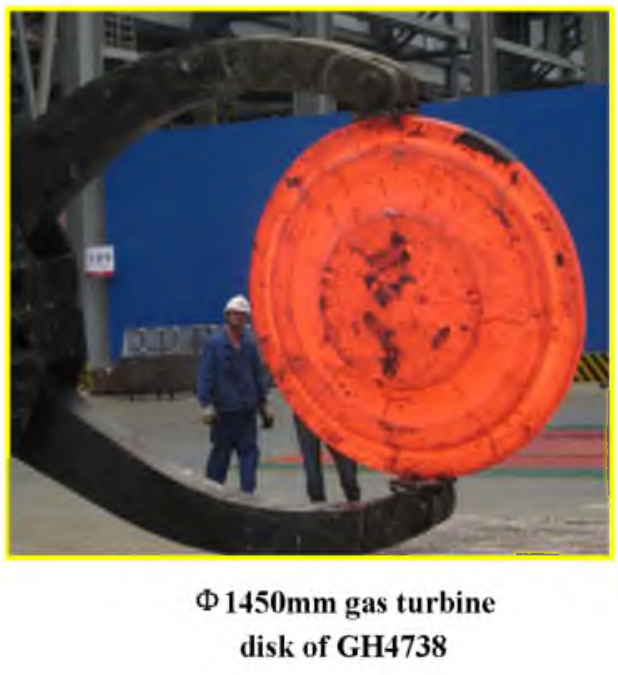

Figure 8. The forging equipment (a) for large-scale $\Phi 1450 \mathrm{~mm}$ gas turbine disk (b) of wrought GH4738 superalloy using microstructure evolution precision control models combined integrated simulation method.

The large forged disk was heat treated using the following thermal cycles $1020^{\circ} \mathrm{C} / 4 \mathrm{~h} / \mathrm{OC}+$ $845^{\circ} \mathrm{C} / 4 \mathrm{~h} / \mathrm{AC}+760^{\circ} \mathrm{C} / 16 \mathrm{~h} / \mathrm{AC}$. Test specimen rings were cut from the disk after heating treatment, the specimen location is shown in Figure 7(d). The microstructure examination results show that its average grain size is about $64-90 \mu \mathrm{m}$, ASTM No. 4-5 or finer (include the average grain diameter), shown in Figure 9. The primary gamma prime is about $160 \mathrm{~nm}$ and second gamma prime is about $30 \mathrm{~nm}$ measured at the center of test ring. Disk mechanical testing of the test ring was also conducted for tensile at room and elevated temperature $540^{\circ} \mathrm{C}$ and stress rupture test at $732^{\circ} \mathrm{C} / 550 \mathrm{MPa}$ at several locations. The mechanical property results are shown in Tables 5,6 and 7. All the mechanical properties meet AMS5704G requirements. In conclusion, the microstructure evolution models and integrated simulation methods of GH4738 alloy have provided a new method for making large-scale disk forgings. 

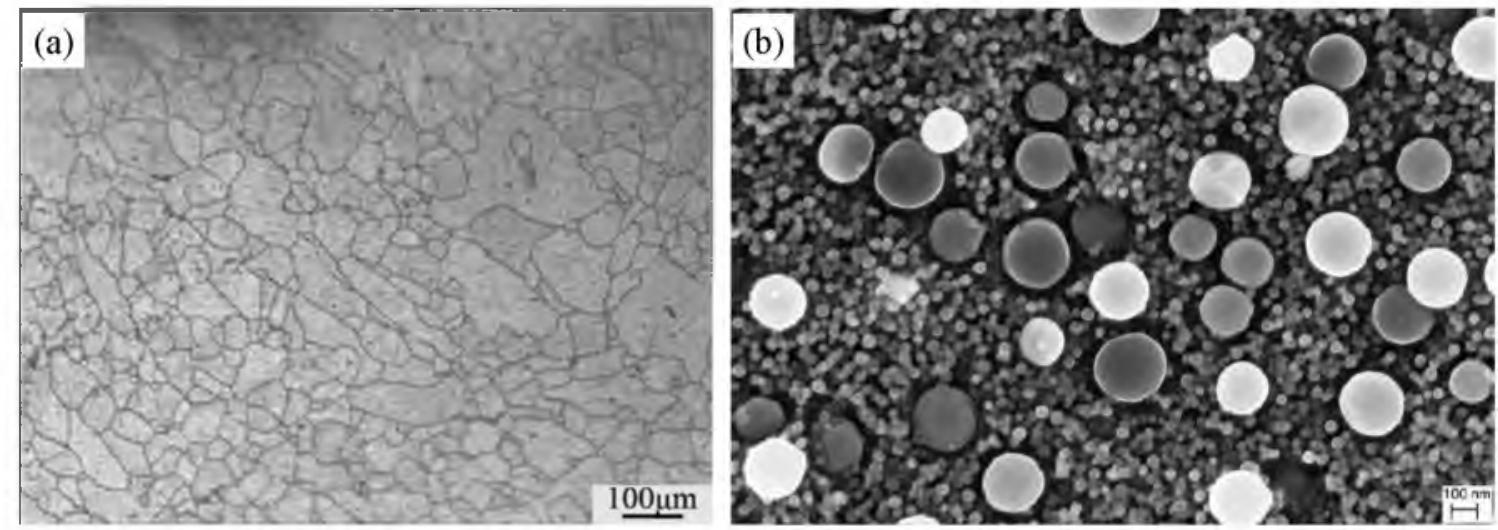

Figure 9. Microstructure of large-scale gas turbine disk of wrought GH4738 superalloy (a) distribution of grain; (b) gamma prime in the center of test ring.

Table 5. Tensile Properties at Room Temperature.

\begin{tabular}{lcccccc}
\hline No & $\begin{array}{c}\text { Test } \\
\text { temperature, } \\
\mathrm{T} /{ }^{\circ} \mathrm{C}\end{array}$ & $\begin{array}{c}\text { Hardness, } \\
\text { HBW }\end{array}$ & $\begin{array}{c}\text { Ultimate } \\
\text { strength, } \\
\mathrm{Rm} / \mathrm{MPa}\end{array}$ & $\begin{array}{c}\text { Yield } \\
\text { Strength, } \\
\mathrm{R}_{0.2} / \mathrm{MPa}\end{array}$ & $\begin{array}{c}\text { Elongation, } \\
\mathrm{A} / \%\end{array}$ & $\begin{array}{c}\text { Reduction } \\
\text { of area, } \\
\mathrm{Z} / \%\end{array}$ \\
\hline $\mathrm{R} 1$ & 23 & 359 & 1343 & 884 & 26.0 & 26.0 \\
$\mathrm{R} 2$ & 23 & 352 & 1345 & 995 & 25.0 & 29.0 \\
$\mathrm{R} 3$ & 23 & 358 & 1258 & 877 & 19.0 & 19.0 \\
$\mathrm{R} 4$ & 23 & 357 & 1313 & 916 & 24.0 & 23.0 \\
\hline $\mathrm{E} 1$ & 23 & 355 & 1287 & 928 & 17.5 & 23.1 \\
$\mathrm{E} 2$ & 23 & 353 & 1257 & 929 & 16.0 & 20.0 \\
$\mathrm{E} 3$ & 23 & 350 & 1335 & 985 & 21.5 & 22.0 \\
$\mathrm{E} 4$ & 23 & 356 & 1317 & 983 & 19.5 & 26.0 \\
\hline
\end{tabular}

Table 6. Tensile Properties at $540^{\circ} \mathrm{C}$ Temperature.

\begin{tabular}{cccccc}
\hline No & $\begin{array}{c}\text { Test } \\
\text { temperature, } \\
\mathrm{T} /{ }^{\circ} \mathrm{C}\end{array}$ & $\begin{array}{c}\text { Ultimate } \\
\text { strength, } \\
\mathrm{Rm} / \mathrm{MPa}\end{array}$ & $\begin{array}{c}\text { Yield Strength, } \\
\mathrm{R}_{0.2} / \mathrm{MPa}\end{array}$ & $\begin{array}{c}\text { Elongation, } \\
\mathrm{A} / \%\end{array}$ & $\begin{array}{c}\text { Reduction of } \\
\text { area, Z/\% }\end{array}$ \\
\hline R1-1 & 540 & 1260 & 845 & 16.5 & 19.5 \\
$\mathrm{R} 1-1$ & 540 & 1280 & 915 & 18.5 & 28.5 \\
$\mathrm{R} 2-1$ & 540 & 1140 & 755 & 20.0 & 17.5 \\
$\mathrm{R} 2-2$ & 540 & 1170 & 795 & 18.5 & 17.5 \\
\hline $\mathrm{E} 3-1$ & 540 & 1210 & 810 & 19.5 & 25.0 \\
$\mathrm{E} 3-2$ & 540 & 1160 & 820 & 16.5 & 19.5 \\
$\mathrm{E} 4-1$ & 540 & 1230 & 870 & 19.0 & 22.0 \\
$\mathrm{E} 4-2$ & 540 & 1200 & 880 & 17.0 & 22.0 \\
\hline
\end{tabular}


Table 7. Combination Stress Rupture Properties at $732^{\circ} \mathrm{C} / 550 \mathrm{MPa}$.

\begin{tabular}{cccccc}
\hline No & Test temperature $\mathrm{T} /{ }^{\circ} \mathrm{C}$ & Stress $/ \mathrm{MPa}$ & Life $/ \mathrm{h}$ & $\delta / \%$ & $\Psi / \%$ \\
\hline R11 & 732 & 550 & 54.0 & 28.0 & 50.1 \\
$\mathrm{R} 11$ & 732 & 550 & 98.7 & 28.0 & 54.2 \\
$\mathrm{R} 21$ & 732 & 550 & 126.1 & 28.0 & 35.1 \\
$\mathrm{R} 22$ & 732 & 550 & 127.0 & 28.0 & 38.2 \\
\hline E31 & 732 & 550 & 88.5 & 25.1 & 30.8 \\
$\mathrm{E} 32$ & 732 & 550 & 85.6 & 27.0 & 32.4 \\
$\mathrm{E} 41$ & 732 & 550 & 65.6 & 27.4 & 35.0 \\
$\mathrm{E} 42$ & 732 & 550 & 68.8 & 23.1 & 30.0 \\
\hline
\end{tabular}

\section{Conclusions}

After a series of experiments and simulation, it has been found that the microstructure evolution and integrated simulation method are reliable. Through these studies, some main conclusions have been drawn as follows:

(1) Microstructure evolution precision control models for GH4738 alloy have been constructed at different deformation conditions and verified by $\$ 300 \mathrm{~mm}$ disk forging experiments.

(2) Integrated simulation method has shown a high correlation with actual microstructure distribution and microstructure evolution can be continuously described during deformation of GH4738 superalloy disk.

(3) The large-scale flue gas turbine disk $\Phi 1450 \mathrm{~mm}$ of GH4738 nickel based superalloy has been successfully forged by hot die forging using $800 \mathrm{MN}$ hydraulic press. Its mechanical properties, such as hardness, tensile properties at room and elevated temperature, $732^{\circ} \mathrm{C}$ stress rupture properties of the large-scale gas turbine disk have reached up to the specification for gas expander HG/T 3650-2012 (equivalent to the level of AMS 5704G).

\section{Acknowledgments}

This project is supported by CNPC Lanzhou Petroleum Processing and Chemical Machinery Plant, China National Erzhong Group Co., Baoshan Iron \& Steel Co. Ltd. The authors would like to acknowledge all of them for collaborative efforts. Correspondent: Maicang Zhang, mczhang@ustb.edu.cn and Zhihao YAO, zhihaoyao@ustb.edu.cn.

\section{Reference}

[1] G.S. Shen, S.L. Semiatin, R. Shivpuri, "Modelling microstructural development during the forging of Waspaloy," Metallurgical and Materials Transactions A, 1995, 26A: 1795-1803.

[2] Z.H. Yao, J.X. Dong, M.C. Zhang, "Microstructure control and prediction of GH738 superalloy during hot deformation I. Construction of Microstructure Evolution Model," Acta Metallurgica Sinica, 2011, 47(12): 1581-1590.

[3] Z.H. Yao, Q.Y. Wang, M.C. Zhang, J.X. Dong, "Microstructure control and prediction of 
GH738 superalloy during hot deformation II. Verification and Application of Microstructural Evolution Model," Acta Metallurgica Sinica, 2011, 47(12): 1591-1599.

[4] K. Karhausen, R. Kopp, "Model for integrated process and microstructure simulation in hot forming," Steel Research. 1992, 63(6): 247-256.

[5] Z.H. Yao, M.C. Zhang, J.X. Dong, "Stress rupture fracture model and microstructure evolution for Waspaloy," Metallurgical and Materials Transactions A, 2013, 44(7): 3084-3098.

[6] Z.H. Yao, J.X. Dong, M.C. Zhang, Q.Y. Yu, "Degradation of microstructure of GH864 superalloy during long exposure at $870^{\circ} \mathrm{C}$," Transactions of Materials and Heat Treatment, 2011, 32(10): 43-49.

[7] L.B. Mandy, H.R. Andrew, "Evaluation of the influence of grain structure on the fatigue variability of Waspaloy. In: Reed R C, Green K A, Caron P, eds. Proceeding of the 11th International Symposium on Superalloy, Superalloys 2008, TMS, Warrendale, PA, 2008, $583 \sim 588$.

[8] Z.H. Yao, J.X. Dong, M.C. Zhang, L. Zheng, Q.Y. Yu, "Study on the hot deformation behaviour of Superalloy GH738," Rare Metal Materials and Engineering, 2013, 42(6): 1199-1204.

[9] D.W. Livesey, C.M. Sellars, "Hot-deformation characteristics of Waspaloy," Materials Science and Technology, 1985, 1: 136 144.

[10]Z.H. Yao, J.X. Dong, M.C. Zhang, L. Zheng, "Relationship between microstructures and properties for GH864 superalloy," Rare Metal Materials and Engineering, 2010, 39(9): $1565-1570$.

[11]M J Donachie, A A Pinkowish, W P Danwsi, et al, "Effect of hot work on the properties on Waspaloy," Metallurgical Transactions, 1970, 1: 2623.

[12] S.L. Semiatin, P.N. Fagin, M.G. Glavicic, et al., "Deformation behavior of WASPALOY at hot-working temperatures," Scripta Materialia, 2004, 50: 625 629.

[13]J.P. Thomas, S.L. Semiatin, "Mesoscale modelling of the recrystallization of Waspaloy and application to the simulation of the ingot-cogging process," Metallurgical and Materials Transactions A, 2006, A 38: 2095-2105.

[14]G. Shankar, Z. Nicholas, "Deformation process design for control of microstructure in the presence of dynamic recrystallization and grain growth mechanisms," International Journal of Solids and Structures, 2004, 41: 2011 2037.

[15]A.A. Guimaraes, J.J. Jonas, "Recrystallization and aging effects associated with the high temperature deformation of WASPALOY and Inconel 718," Metallurgical Transactions A, 1981, 12: $1655 \sim 1666$.

[16]C.M. Sellars, "Modelling microstructural development during hot rolling, Materials Science and Technology, 1990: 1072-1081.

[17]H. Yada, Proc. Int. Symp. Accelerated cooling of rolled steel[C], Conf of Metallurgists, CIM, Winnipeg, MB, Ruddle G.E Crawley and A F, Canada, 1987: 105-120.

[18]D. Devadas, I.V. Samarasekera, E.B. Hawbolt, "The thermal and metallurgical state of steel strip during the forging hot rolling: Part III, Microstructural Evolution," Metallurgical Transactions A, 1991, 22: 335-348.

[19]S.G. Xu, Q.X. Cao, "Numerical simulation of the microstructure in the ring rolling of hot steel," Journal of Materials Processes of Technology, 1994, 43: 221-235. 
[20]Z.H. Yao, J.X. Dong, X. Chen, M.C. Zhang, L. Zheng, "Gamma prime phase evolution during long-time exposure for GH738 superalloy," Transactions of Materials and Heat Treatment. 2013, 34(1): 31-37.

[21]Z.H. Yao, J.X. Dong, M.C. Zhang, "Effects of microstructure on fatigue crack propagation rate for GH864 alloy," Journal of University of Science and Technology Beijing, 2011, 33(12): 1501-1507.

[22]Z.H. Yao, J.X. Dong, M.C. Zhang, Q.Y. Yu, L. Zheng, "Effect of solution temperature on microstructure and properties of GH864 alloy," Transactions of Materials and Heat Treatment, 2011, 32(7): 44-50.

[23]Z.H. Yao, Q.Y. Wang, M.C. Zhang, J.X. Dong, "Numerical simulation of microstructure evolution during GH864 alloy disc forging," Forging and Stamping Technology, 2011, 36(3): $1-7$ 